graphy of the head in children should be used only after careful clinical consideration. We do not believe, however, that an examination of the head by computed tomography in a child presents a serious threat to intellectual development.

\section{Paul D Griffiths professor of radiology, University of Sheffield}

Section of Academic Radiology, Royal Hallamshire Hospital, Sheffield S102JF (p.griffiths@sheffield.ac.uk)

Giles D Morrison radiology protection adviser

Sheffield Teaching Hospitals NHS Trust, Sheffield S5 7AU

Competing interests: None declared.
1 Hall P, Adami H-O, Trichopoulos D, Pedersen NL, Lagiou P, Ekbom A, et al. Effect of low doses of ionising radiation in infancy on cognitive function in adulthood: Swedish population based cohort study. BMJ tion in adulthood:

2 Leitz W,Jonsson H. Patient doses from X-rays in Sweden-a summary of results from health care reports in 1999 [in Swedish]. Stockholm: Swedish Radiation Protection Institute, 2001

3 Chapieski L, Friedman A, Lachar D. Psychological functioning in children and adolescents with Sturge-Weber syndrome. J Child Neurol 2000; $15: 660-5$.

4 Abu-Arafeh I, Russell G. Prevalence and causes of headache in schoolchildren. BMJ 1994;309:765-9.

5 Haslam RA. Headaches. In Behrman RE, Kliegman RM, Jenson HB, eds. Nelson textbook of pediatrics 16th ed. Philadelphia. WB Saunders, Nelson textbook
2000:1834.

6 National Institute for Clinical Excellence. Epilepsy-full guideline, first consultation. Draft for first consultation. London: NICE, 12 December 2003. www.nice.org.uk/pdf/Epilepsy_FULL_guideline_first_consultation.pdf (accessed 24 Aug 2004)

\title{
Back to the future?
}

\section{From April 2005 individual general practices can apply to commission services}

$\mathrm{T}$ The NHS Improvement Plan and new Department of Health guidance sets out proposals to revive commissioning by individual general practices of health services in the NHS in England, as part of a commitment to explore and evaluate new models of devolved commissioning. ${ }^{12}$ From April next year, any general practice that so desires can obtain an indicative commissioning budget from their primary care trust.

We have been here before. For many people, practice based commissioning will seem to be simply general practice fundholding rebadged. The new proposals bear striking similarities to fundholding, sharing such characteristics as budget holding by general practices, commissioning freedoms for individual practices, and direct financial incentives for general practitioners. Fundholding was, perhaps, the most contested element of the NHS internal market setup by the last Conservative government and was opposed bitterly by the opposing Labour Party. The creation in 1999 of collective primary care commissioning through primary care groups (which evolved into primary care trusts) was proposed as an antidote to the perceived drawbacks of fundholding, in particular, inequities in access to elective care and high transaction costs. So why should a Labour government court controversy by rekindling interest in such a similar policy now?

Three compelling reasons may be behind this apparent shift in policy. ${ }^{3}$ Firstly, a widespread belief prevails that primary care trusts are failing to have sufficient impact as commissioners of hospital care. ${ }^{4}$ Such failure is gaining in importance as NHS trusts convert to foundation hospitals and gain greater freedom, and as new incentives for cost-per-case contracting are introduced to the NHS through the new policy Payment by Results. ${ }^{5}$ Second, frontline primary care clinicians may not be sufficiently engaged with the work of their primary care trusts, or may perceive that they wield little influence over the actions of those trusts. $^{6}$

The third and perhaps most important reason lies in the UK government's anxieties over demand management. The current push to shorten waiting times for treatment while increasing the capacity of the NHS may result in rapid growth in patients' demands for services. Practice based commissioning is intended to re-engage clinicians (particularly, but not exclusively, general practitioners) in the process, and the related financial incentives are intended to encourage general practitioners to scrutinise their referrals to hospital and to seek ways of enhancing primary care to prevent avoidable admissions to hospital. The new public service agreement target to reduce days spent in hospital for emergencies by $5 \%$ by 2008 is also concentrating minds. ${ }^{7}$

So what can we learn from our experiences in the past? A systematic review of research on fundholding during the mid 1990s was equivocal about the benefits of the scheme. ${ }^{8}$ However, research published after the demise of fundholding has allowed a more fulsome appraisal of the initiative. For example, one important study concluded that patients referred through fundholding experienced waiting times for treatments that were $8 \%$ shorter than those for corresponding patients of non-fundholding general practitioners. ${ }^{9}$ Another study, based on admission data for four years, showed that fundholders reduced admission rates for elective procedures by $3.3 \%$ compared with nonfundholders. ${ }^{10}$ The Achilles heel of small-scale, commissioning by practices has often been seen to be the management of financial risk. However, research into "total purchasing" pilots (extended fundholding schemes incorporating a broader range of services and often involving more than one practice) showed that single practices and small multipractice groups managed these risks better than large multipractice ventures. ${ }^{11}$

Despite such evidence, many will be anxious about the return of anything resembling fundholding. Yet the new incarnation of commissioning by practices may be able to avoid at least some of the main pitfalls of unfair access to services and high administrative costs. The NHS has changed considerably since the heyday of fundholding. The Payment by Results policy introduces a standard price tariff and a new mechanism for contracting, and opportunities for individual general practice commissioners to negotiate advantageous 
prices (to the disadvantage of other general practitioners and patients) are therefore disappearing. The national tariff should also reduce transaction costs. Primary care trusts will act as the contracting agent for commissioners in practices, streamlining the process and reducing costs still further and the additional costs of practice based commissioning will be funded from savings against the budget. Unlike fundholding doctors, the new practice based commissioners will not be legally autonomous and will remain under the aegis of primary care trusts. This will provide an opportunity to marry the dynamism of devolution with the strategic planning and public accountability of primary care trusts. Practices that commission services in the new scheme are less likely to be seen as "wild cards" as they were in the $1990 \mathrm{~s}^{12}$

Nor will the patients of these new commissioners enjoy access to a far wider range of services. There are now guarantees of greater choice for all patients and, from 2008, patients will have unrestricted choices to see any provider meeting minimum quality standards and the NHS price tariff. ${ }^{1}$ Furthermore, since the demise of fundholding, the NHS has worked to decrease variation in services across the country. National service frameworks, guidelines from the National Institute for Clinical Effectiveness, inspections by the Healthcare Commission, and new national core and developmental quality standards are all aiming to regulate the services available to NHS patients. This new environment might allay the fears of all save the most hardened critics of fundholding.

Richard Q Lewis visiting fellow

King's Fund, London W1G 0AN

(R.lewis@kingsfund.org.uk)

Competing interests: The author has advised NHS organisations on practice based commissioning as a paid consultant.

1 Department of Health. NHS improvement plan-putting people at the heart of public services. London: $\mathrm{DoH}, 2004$

2 Department of Health. Practice based commissioning. Engaging practices in commissioning. London: DoH, 2004. (http://www.dh.gov.uk/assetRoot/ 04/09/03/59/04090359.pdf (accessed 6 Oct 2004).

3 Lewis R. Primary care led commissioning-harnessing the power of the primary care front line. London: King's Fund, 2004 wwwkingsfund.org.uk/pdf/practiceledcommissioning pdf (accessed Oct 2004).

4 Commission for Health Improvement. What CHI has found in primary care trusts-sector report. London: CHI, 2004 .

Department of Health. Reforming NHS financial flows. Introducing payment by results. London: $\mathrm{DoH}, 2002$.

by results. London: $\mathrm{DoH}, 2002$.
NHS Alliance/Primary Care Report. Clinician engagement: a national NHS Alliance/Primary Care Report.
survey. Retford: NHS Alliance, 2003.

HM Treasury. Public service agreements 2004. www.hm-treasury.gov.uk spending_review/spend_sr04/psa/spend_sr04_psaindex.cfm (accessed 1 October 2004).

8 Goodwin N. GP fundholding. In: Le Grand J, Mays N, Mulligan, JA, eds. Learning from the NHS internal market-a review of the evidence. London: King's Fund, 1998.

9 Propper C, Croxson B, Shearer A. Waiting times for hospital admissions: the impact of GP fundholding. CMPO Working Paper Series No 00/20, 2000.

10 Dusheiko M, Gravell H, Jacobs R, Smith P. The effects of budgets on doctor Dusheiko M, Gravell $\mathrm{H}$, Jacobs R, Smith $\mathrm{P}$. The effects of budgets on doctor
behaviour: evidence from a natural experiment, discussiom paper. York: Department of Economics, University of York, 2003

11 Baxter K, Bachmann M, Bevan G. Primary care groups: trade-offs in managing budgets and risk. Public Money Manage 2000;Jan-Mar:53-62.

12 Glennerster H, Matsaganis M, Owens P. Implementing GP fundholding. wild card or winning hand? In: Robinson R, Le Grand J, eds. Evaluating the NHS reforms. London: King's Fund, 1994.

\section{Safety of antipsychotic drugs for pregnant and breastfeeding women with non-affective psychosis}

\section{Multicentre cohort studies are needed as randomised trials are impractical}

$\mathrm{A}$ round $2 \%$ of women develop a non-affective psychotic disorder, and more than half of them have children. ${ }^{12}$ Women with nonaffective psychoses are less fertile than controls, partly because of hyperprolactinaemia secondary to antipsychotic drugs. ${ }^{3}$ The use of atypical drugs such as clozapine and olanzapine, which do not have this effect, may increase fertility rates. Weighing risks against benefits in treating pregnant and breastfeeding women with antipsychotics requires assessment of clinical effectiveness versus risk of toxicity to mother, fetus, newborn, and the developing child. Withholding antipsychotic treatment may expose mother and fetus to more harm than benefit as, in addition to behavioural disturbance which may put both at risk, physiological changes associated with psychosis could affect fetoplacental integrity and development of the central nervous system. Subsequently, poor clinical outcomes for mothers may result in poorer interaction between mother and infant. ${ }^{5}$ But the impact of antipsychotic medication on the fetus is also unclear as no randomised controlled trials have evaluated the use of antipsychotics in pregnancy. ${ }^{6}$

The only large controlled studies of antipsychotics in pregnancy have been conducted on women with medication (generally drugs such as phenothiazines) are used for these patients than for patients with schizophrenia, and residual confounding is commonplace. Conclusions are therefore limited. A metaanalysis reported that exposure to low potency antipsychotics during the first trimester was associated with a small additional risk of congenital anomalies. ${ }^{7}$ Antipsychotics can also produce toxic effects in newborn infants medicated in the womb, including respiratory depression and neonatal behavioural abnormalities such as extrapyramidal movements and difficulty with oral feeding, although these effects usually resolve within days. The few small studies examining longer term neurobehavioural effects in children exposed to antipsychotics in the womb have reported no behavioural or intellectual abnormalities.

Even less is known about any adverse effects of atypical antipsychotics. On comparing case registry data $(n=37)$ with historical controls the rates of adverse effects with olanzapine during pregnancy were not found to be higher. ${ }^{8}$ However, data from the National Teratology Information Service indicate an increased incidence of malformations of 10\% (compared with an expected incidence of 2-3\%). ${ }^{9}$ However, as only three cases were seen, no clear relation can be 